\title{
NARRATIVAS DA FORMAÇÃO DE PROFESSORAS ASSENTADAS NO SEMIÁRIDO BRASILEIRO
}

\author{
Pedro Paulo Souza Rios ${ }^{1}$ \\ André Ricardo Lucas Vieira ${ }^{2}$
}

\section{INTRODUÇÃO}

O presente trabalho evidencia a trajetória de formação de uma professora assentada, tendo por base as concepções teórico-metodológicas das narrativas (auto)biográficas, as nuances da formação centrada na tríplice: gênero, docência e formação. É importante dizer que os estudos a partir do desdobramento de gênero e docência ainda são incipientes no contexto brasileiro, sendo demarcado pelos estudos de Denice Barbosa Catani (1997) e Guacira Louro (2007), que colocam em evidência o gênero e suas intersecções com o trabalho docente.

A escolha pela narrativa de vida da professora assentada, enquanto objeto de estudo dar-se-á, por ser o movimento social uma organização intrinsicamente comprometido com os processos que garantam a formação autônoma dos sujeitos, além de considerar o assentamento como um espaço social caracterizado por maiores possibilidades de aceleração dos processos de mudança social que se manifestam através da confluência de diferentes atores que interagem com o objetivo claro de mudar a condição sócio econômica das famílias assentadas.

No assentamento, a escola enquanto espaço social se apresenta como locus privilegiado para a formação dos sujeitos, sendo, portanto um espaço atravessado pelas representações de gênero (LOURO, 2007). Dessa maneira, a categoria gênero, no Brasil e em várias partes do mundo, antes considerada secundária, assume lugar de destaque na compreensão de alguns fenômenos contemporâneos, a saber, a feminização de determinadas profissões, a exemplo do magistério.

\footnotetext{
${ }^{1}$ Universidade do Estado da Bahia - UNEB. E-mail: peudesouza@yahoo.com.br

${ }^{2}$ Universidade do Estado da Bahia - UNEB. E-mail: sistlin@uol.com.br
} 


\section{GÊNERO E DOCÊNCIA NO BRASIL}

A história da educação no Brasil parece coincidir com a história da discriminação de gênero. A sociedade brasileira no seu processo de formação foi profundamente marcada pelo modelo patriarcal e autoritário, além disso, teve a influência da Igreja Católica e essas influências refletem diretamente na constituição dos modelos educacionais no país, dos quais as mulheres foram excluídas. Segundo Ribeiro (2000), na tradição cultural ibérica, transposta de Portugal para a colônia brasileira, a mulher era considerada um ser inferior, que não tinha necessidade de aprender a ler e a escrever. A educação era tutelada pela Igreja Católica reforçando o espírito medieval.

Somente no século XX, com a Revolução de 1930 é que essa situação começa a ser revertida. Nesse período surgem às primeiras medidas voltadas para a educação de massa e com isso, o acesso das mulheres à escola começa a ser facilitado, constituindo maioria dos alunos nas escolas normais (CATANI, et al. 1997), contudo é só com a LDB (Lei de Diretrizes e Bases da Educação Brasileira) de 1961 que passa a ser garantido acesso igualitário ao ensino superior para as mulheres que cursavam o magistério, através da equivalência de todos os cursos de nível médio (BELTRÃO; ALVES, 2004). Mas é com a constituição de 1988 e com a redemocratização do país que se percebe a incorporação de demandas sociais específicas na legislação. Assim, este é um momento singular para os grupos sociais e especificamente para o movimento feminista.

Nesse período, a discussão sobre a desigualdade de sexos na educação se restringia ao acesso igualitário entre meninas e meninos. Dessa maneira o conceito de gênero está fora de cogitação dentro dessa discussão, devido ao momento histórico de que estamos falando, já que nesse período o conceito ainda estava sendo introduzido no próprio movimento popular de mulheres. Foi nesse contexto, na década de 1990, que foram elaboradas a Lei de Diretrizes e Bases da Educação (Lei n. 9.394/1996) e os Parâmetros Curriculares Nacionais para o Ensino Fundamental - PCN. Acreditamos que essa demarcação histórica seja importante para que possamos compreender a trajetória das mulheres no âmbito da educação formal. 


\section{ESCOLA ESPAÇO DE CONSTRUÇÃO DA IDENTIDADE DE GÊNERO}

A análise da identidade de gênero isolada de outras experiências pessoais é insuficiente para a compreensão das representações de poder ligadas intrinsecamente às construções das identidades (LOURO, 2000). A autora salienta que elas se constroem durante a vida do indivíduo, já sendo iniciado no seu nascimento, nas relações que são estabelecidas entre a criança e as pessoas com quem convive, sejam elas outras crianças, adolescentes ou adultos, e também entre a criança e os diversos objetos culturais aos quais tem acesso. Dessa forma, a escola é sem dúvidas um espaço propício para a construção das relações de gênero.

Poderíamos dizer então que a escola é tanto feminina quanto masculina, pois transitam no seu interior muito mais do que homens $\mathrm{e}$ mulheres, transitam pessoas com todas suas complexidades étnicas, classe social, religião, orientação sexual, partido político, dentre outras. Segundo Louro (2007, p.89) "é possível argumentar que ainda que as agentes do ensino possam ser mulheres, elas se ocupam de um universo marcadamente masculino."

\section{PERCURSO METODOLÓGICO: NUANCES DA NARRATIVA NA FORMAÇÃO}

Compreender a trajetória de vida de uma professora assentada, tendo por pressupostos à narrativa, a partir dos processos formativos é o que propomos nesta pesquisa, pois entendemos que os sujeitos em sua formação profissional precisam estabelecer conexões e desenvolver competências não somente com o fazer pedagógico, essas são necessárias também nas relações sociais que se estabelece com os contextos específicos (NÓVOA, 1992). Para tanto, considera-se que o método e os procedimentos utilizados em uma pesquisa não podem ser vistos como escolhas ao acaso e fora do contexto, ao contrário, métodos e procedimentos precisam necessariamente estar vinculados ao objeto de estudo em questão e à posição teórica do próprio pesquisador. 
Há quase três anos mantemos contato com a professora Jitirana ${ }^{3}$. Os primeiros contatos aconteceram em 2013. Na época estava no processo de pesquisa etnográfica para a escrita da minha dissertação no mestrado em Educação, Cultura e Territórios Semiáridos.

Tivemos dois momentos para a gravação das narrativas com a professora. A primeira foi uma narrativa corrida que durou mais de 35 minutos entre pausas emocionadas, voz entrecortada, lágrima que rolou sutil rasteiramente sobre sua face e até choros mais tensos. Cada lembrança, cada fala, era seguida de uma reflexão sem julgamentos. Dessa forma compreendo que $o$ ato de falar de si pode restaurar o sentimento de domínio de sua própria vida, da mesma forma que pode recuperar a integralidade de sua personalidade (CATANI et al. 1997), ao tempo em que se configura em fonte de conhecimento na formação de professores/as.

\begin{abstract}
Essa história da faculdade, de estudar pedagogia é interessante. No início eu percebi quase a mesma coisa do magistério, quando me olhavam diferente. $O$ fato de você sair do assentamento [...] pra estudar fora é um novo desafio se apresenta pra mim [...] Desde o início da minha formação nada foi fácil em minha vida, a cada etapa eu preciso superar um monte de barreiras, passando por toda discriminação que falei no começo até a condição financeira, foi e está sendo preciso muita força de vontade, te juro que tem dia que dar vontade de jogar tudo pra cima, mas aí eu penso: desisti agora? Não! A vida é um constante processo de formação.
\end{abstract}

No fragmento acima, a professora Jitirana nos relata os desafios superados na sua trajetória de formação, ao tempo em que evidência a intrínseca relação entre sua formação e sua trajetória de vida junto ao movimento social:

Quanto a minha formação não posso negar que o movimento ajuda muito a gente nesse processo. [...]. Os colegas da faculdade que não participam de movimentos não entendem nada de conjuntura social, de questões de gênero, raça, questões ambientais, capitalismo e a gente do movimento dá um show. O movimento é uma escola pra gente.

Dessa maneira podemos verificar que a formação da professora transita entre os espaços de educação formal, por meio da escola e da

\footnotetext{
${ }^{3}$ Jitirana é o nome fictício escolhido pela professora durante nossas entrevistas. Jitirana é uma planta trepadeira típica das regiões tropicais e subtropicais, muito conhecida no Nordeste do Brasil.
} 
universidade, e os espaços formativos não formal, a exemplo do movimento social.

Quando voltei ao Assentamento propondo que ela narrasse sua trajetória de vida escolar e docência, confesso que não foi uma das tarefas mais fáceis, já que a proposta metodológica se apresentava sob outros prismas.

Quando tu me falou, semana passada, sobre essa entrevista eu fiquei pensando na minha história de vida e vi que tem coisa que doe muito. Uma das coisas que eu não gosto de lembrar é da época de escola, pois eu sofri muito. Dói muito até hoje.

A dor da professora Jitirana, tanto tempo depois, podia ser visualizada nas lágrimas que rolam sobre sua face durante a entrevista. Por vários momentos esse cena se repetiu, dando pequenas pausas à entrevista. Por um instante tudo ficava estático em meio às memórias de "uma mulher determinada, meiga, professora, casada, mãe, lavradora e assentada", como ela mesma se definiu.

Nossa investigação será em torno da narrativa (auto)biográfica, focando a formação, assim, optamos por trabalhar com instrumentos de pesquisa que nos permitissem investigar essas relações em profundidade. Considerando as características desta pesquisa, ressaltamos a importância de estarmos abertos e flexíveis para captar a importância do significado daquela informação específica para responder nossa questão orientadora do estudo. Estamos falando das abordagens qualitativas em pesquisa na educação.

As narrativas (auto)biográficas enquanto instrumento e procedimento de pesquisa, encontra sentido e razão de ser, no fato que a história de vida de uma pessoa tende a desvelar elementos para além de simples acontecimentos, caracterizando-se como forma de absorção e análise dos contextos que constituem histórica e humanamente cada sujeito, uma vez que todas as narrações autobiográficas relatam um corte horizontal ou vertical, uma práxis humana (FERRAROTTI, 2014).

Em pesquisas que tem por base as narrativas autobiográficas, no plano da interioridade, a pessoa que narra se deixa levar pelas associações livres para evocar as suas experiências e organizá-las numa coerência narrativa em torno da sua formação e, no plano da exterioridade, a socialização 
da autodescrição de um caminho, com as suas continuidades e rupturas, envolve competências verbais e intelectuais que estão na fronteira entre o individual e o coletivo (JOSSO, 2004). As pesquisas nessa área de conhecimento adotam "as narrativas de formação como um movimento de investigação-formação, seja na formação inicial ou continuada de professores/professoras ou em pesquisas centradas nas memórias e autobiografias de professores." (SOUZA 2006, p. 137).

Nessa perspectiva, Souza (2006) afirma que o trabalho centrado na abordagem (auto)biográfica como uma prática de investigação/formação se justifica pela constante relação "dialética entre as dimensões prática e teórica, as quais são expressas através da meta-reflexão do ato de narrar-se, dizer-se de si para si mesmo como uma evocação dos conhecimentos das experiências construídos pelos sujeitos" (p. 140).

\section{NARRATIVAS DA FORMAÇÃO DOCENTE: SER PROFESSORA NA ROÇA}

As memórias da professora Jitirana, ao revisitarem o passado, possibilitou reorganizar vivências significativas e até adormecidas em suas trajetórias de vida e de formação, que se mesclavam às identidades experienciadas da aluna e da professora, se configurando numa escuta atenta ás crises, na tentativa de valorizar as experiências subjetivas, buscando dar voz à professora Jitirana, permitindo que ela se ouça e se faça ouvir (CATANI, et al. 1997) num processo permanente e reflexivo capaz de se reconhecer em outras histórias de vida.

\footnotetext{
Eu costumo dizer que minha história é a história da maioria das pessoas pobres da minha geração e do meu convívio: família grande, casa cheia e muita criatividade para vencer na vida, mas eu acredito que isso já ajuda a gente a ser resistente [...] Não foram poucas as batalhas que eu já enfrentei nessa vida, mas o mais importante é que estou aqui, viva, ainda que tenham coisas que doem em mim, que eu sinto que não foram cicatrizadas [...] o que esperar de uma pessoa que é mulher, negra, sem terra? Eu acho que tudo isso me motivou a ser professora (Jitirana).
}

O fragmento acima descreve com propriedade o modelo familiar predominante entre as famílias pobres da zona rural do interior do Brasil, com maior incidência no Nordeste, entre as décadas de 1960 até meados da 
década de 1990 (FISCHER, 2006), que para enfrentar às adversidades da vida, eram necessários driblar um modelo de sociedade baseada nos pilares eurocêntrico, urbano, machista, preconceituoso e excludente. Nesse contexto, estudar para as classes populares, era quase sempre era a ultima opção.

\begin{abstract}
A educação na minha vida não chegou facilmente. Vou tentar falar um pouco sobre minha vida escolar, que é um pouco triste [...]. A gente ajudava nossa mãe vender verdura e quando chegava na escola a gente tava fedendo a verdura e uma colega falou que a gente tava fedendo a coentro podre. Ela gritou na escola: "Vixe que fedor de coentro! Tá um fedor de coentro enorme aqui na escola. A gente passou a ser conhecida como as fedorentas da escola, isso me machuca até hoje porque a própria escola acabava contribuindo para que isso continuasse [...] a gente caminhava quase quatro quilômetros todos os dias pra ir e vim pra escola [...] com chuva, sol, frio, calor e mesma a gente sendo discriminado a gente ia pra escola.
\end{abstract}

Sua narrativa transpõe os limites de uma fala mórbida e sem emoção, provocando todos os sentidos numa escuta atenta, sensível, rica em detalhes, carregada de sabores e cheiros. Assim, ao revisitar as memórias da professora Jitirana lanço um olhar sobre suas trajetórias desde a sua formação escolar até o exercício da profissão docente no campo, fazendo emergir, a partir das narrativas, uma reflexão sobre as experiências humanas no campo da educação.

Dessa maneira, as representações que se referem aos significados dentro de uma cultura, estão necessariamente imbuídos de um entre-lugar identitário e discursivo (RIOS, 2011) considerando os aspectos objetivos e subjetivos na formação dos sujeitos, sendo evidenciado na fala da professora Jitirana:

Trabalhar na roça tem um diferencial dos professores da cidade,
principalmente pra gente do movimento, porque aqui nós trabalhamos
as questões ligadas com a realidade do povo do campo, tem uma
pauta bem específica. A gente costuma trabalhar uma educação
contextualizada, voltada para as políticas do campo, já a cidade
pensa uma educação voltada para a realidade deles. Aqui a gente
pensa numa educação que leve em consideração a vida da gente,
percebendo que cada um tem suas diferenças e que nossa luta é
outra, já na cidade não é como se todo mundo fosse igual, é a
mesma coisa pra todo mundo e não ver a realidade do povo e aqui no
campo a gente faz a adaptação com relação à realidade da gente e
dos alunos [...]. Conforme Rios (2015, p. 21), "analisar a docência na roça implica refletir sobre os modos de vida produzidos neste espaço traduzidos na maneira 
como os(as) docentes (re)constroem suas identidades". Dessa maneira, as "lembranças e experiências vividas [...] quando exteriorizadas, representam um passado já re-elaborado nas asas de um tempo" (SOUZA, 2001, p. 17). Nessa perspectiva a memória é acionada, dando possibilidade de vivenciar experiências que forma extremamente significativa tanto no aspecto positivo quanto negativo, possibilitando, por exemplo, reencontrar pessoas que fizeram ou ainda fazem parte da nossa trajetória de vida.

Fazer memória da própria história possibilitou a professora Jitirana, refletir acerca da sua própria formação docente, tomando consciência de cada momento e de cada opção feita, assumindo a docência enquanto compromisso que extrapola o aspecto profissional, tornando-a cidadã comprometida com a própria comunidade:

Eu acredito que ser uma futura pedagoga é tudo. A pedagogia ajuda a gente a compreender o mundo e fazer algo pra o lugar que a gente vive ser melhor, e mais justo, e é isso que tenho buscado a cada formação que venho fazendo. Eu passo a entender o mundo e as coisas ao redor, entender, por exemplo, que as mulheres têm direitos sociais e políticos e até sexuais [...] Você não sabe a alegria que eu tenho em ser pedagoga, não é um curso que eu fiz por fazer, eu faço porque eu gosto mesmo. Eu estou na área que eu quero e assim poder contribuir para que o mundo seja melhor [...] além disso trabalho onde gosto, na roça, com o povo do campo [...]

As palavras da professora nos provocam a pensar sobre o que somos num processo dinâmico e permanente, nos constituindo enquanto sujeitos na sua integralidade. De acordo com Catani, Bueno, Sousa e Souza (1997, p. 40), "o falar de si pode restaurar o sentimento de domínio de sua própria vida, da mesma forma que pode recuperar a integralidade da sua personalidade", fazendo emergir questões tais como identidade de gênero, conforme a narrativa da professora Jitirana:

[...] Eu agora eu posso ver que o processo que eu fiz me ajudou e muito na minha emancipação. Hoje eu posso dizer que sou uma mulher empoderada e isso muda muito a forma que eu vejo o mundo. Aqui em casa não tem essa do marido achar que é ele quem manda. A gente decide as coisas juntos, os dois. Posso te dizer que hoje me sinto mais confiante e segura daquilo que sou [...] Eu costumo dizer que a educação muda as pessoas, a gente se torna mais independente, já que também consegue arranjar emprego mais fácil. A gente ver isso bem claro aqui na área. As mulheres que tiveram alguma formação, eu digo até o ensino médio, por exemplo, 
consegue um emprego mais fácil, e isso dar, a nós mulheres, mais autonomia, a gente não fica tão dependente do marido.

Em várias partes da narrativa a professora Jitirana fez questão de deixar claro que o seu processo de formação, para além dos limites da escola e posteriormente a exercício da docente a ajudaram a se perceber enquanto mulher, negra, lavradora, assentada, esposa e mãe, o que evidencia sua capacidade de interseccionar as questões inerentes à identidade de gênero.

$O$ ato de narrar a própria história de formação possibilitou, a professora Jitirana, adentrar-se a si mesma, conhecendo suas potencialidades e fragilidades, ao tempo que ofereceu matéria prima para a reflexão e reelaboração de novas praticas pedagógicas, não estanques em si, mas constituindo-se em links na elaboração de significados acerca dela mesma enquanto mulher e docente.

\begin{abstract}
Pensar em coisas que eu não queria pensar, ainda dói muito em mim [...]. São lembranças tristes e tem coisas que eu fico pensando e refletindo pra que não fazer com meus alunos, agora eu tenho a certeza de querer ser diferente, pensar minha própria história de ajudou a ver como era a educação que eu tinha e a educação que eu quero para meus filhos e meus alunos.
\end{abstract}

Ao considerar as narrativas de vida, da professora Jitirana buscouse valorizar seu processo de desenvolvimento profissional e pessoal, fazendo com que ela se sentisse sujeito da sua formação que ajude a enfrentar os dilemas educativos atuais, conforme sinaliza Nóvoa (2014), ao tempo em que provoca a educação a se pensar de maneira equitativa e complexa.

\title{
À GUISA DA CONCLUSÃO: OS AROMAS DE UMA FORMAÇÃO
}

A vida humana é composta por ciclos que se desembocam em ritos de passagens seguidos quase sempre por um ritual, podendo esse ser sagrado ou profano. Alguns ciclos são demorados, outros mais rápidos, outros estão sempre inclusos, podendo ser classificados como contínuos. Esses nunca se dão por encerrados completamente, mas se fazem de ciclos dinâmicos e inacabados, a exemplo da formação docente. Não há um início e um fim, mas um processo que vai sendo desvelado cotidianamente carregado de aromas bons e ruins como nos narra a professora Jitirana. 
Conhecer aspectos do percurso da vida pessoal e profissional construído por Jitirana, foi uma experiência singular, mesmo considerando o fato de conhece-la e de já ter feito pelo menos quatro entrevistas semiestruturada anteriores. A narrativa se apresentou tanto pra mim quanto ela numa outra experiência $e$ isso contribuiu significativamente para que realizássemos reflexões ricas e produtivas acerca da formação e da trajetória profissional de docentes. Não é nossa intenção esgotar o assunto com esse estudo, já que ainda há muitas coisas a serem ditas, lembranças a serem recobradas, experiências a serem partilhadas, aromas e odores a serem descobertos.

As narrativas não serviram apenas para que Jitirana refletisse sobre sua trajetória de vida e formação, possibilitou a reflexão acerca do seu auto reconhecimento identitário enquanto mulher, negra, mãe, lavradora. Dessa maneira, o enfoque (auto)biográfico provoca um olhar para si mesma, para sua prática e sua trajetória de vida.

Assim, pude perceber que a formação de um/a professor/a não dar meramente via universidade, mas, sobretudo, pelas relações interpessoais e profissionais estabelecidas, pelas experiências cotidianas, pelo ambiente familiar, pelos movimentos sociais e comunitários e pela convergência entre a teoria e a prática pedagógica. Nesse sentido acreditamos que tal consideração é fundamental para a análise do processo de formação de outros docentes.

\section{REFERÊNCIAS}

BELTRÃO, K.I; ALVES, J.E.D. A rever são do hiato de gênero na educação brasileira no século XX. ABEP, 2004. Disponível em <http://www.metas2015.unb.br/Documentos/Educacao\%20Universal/Reversao \%20do\%20hiato\%20de\%20genero\%20na\%20educacao.pdf>.

CATANI, Denice Barbara (Org.). Docência, memória e gênero. Estudos sobre a formação. São Paulo: Escrituras Editora, 1997.

FERRAROTTI, F. Sobre a autonomia do método biográfico. In: NÓVOA, A; FINGER, M. O método (auto)biográfico e a formação. EDUFRN, Natal, 2014. p. $29-55$. 
JOSSO, M. C. Experiências de vida e formação. São Paulo, Cortez, 2004.

Lei de Diretrizes e Bases da Educação Nacional. Lei no 9.394, de 20 de dezembro de 1996. Disponível em:<

http://portal.mec.gov.br/arquivos/pdf/ldb.pdf.>

LOURO, Guacira Lopes. Gênero, sexualidade e educação: Uma perspectiva pós-estruturalista. Petrópolis: Vozes, 2007.

Editora, 2000.

. Currículo, Gênero e Sexualidade. Porto, Portugal: Porto

NÓVOA, António. Formação de professores e profissão docente. In: NÓVOA, António (Coord.). Os professores e a sua formação. Lisboa: Dom Quixote, 1992. p. 13-33.

. A formação tem que passar por aqui: as historias de vida no Projeto Prosalus. In: O método (auto)biográfico e a formação: NÓVOA, António; FINGER, Mathias (orgs). Tradução Maria Nóvoa. $2^{\mathrm{a}}$ ed. Natal, UDUFRN, 2014.

Parâmetros Curriculares Nacionais para o Ensino Fundamental - PCN, 1997. Disponível em:<http://portal.mec.gov.br/seb/index.php?option=content\&task= view\&id=263\&ltemid=253.>

RIBEIRO, Maria Luisa Santos. História da educação brasileira: a organização escolar. 9. ed. São Paulo: Cortez A.A., 2000.

RIOS, Jane Adriana Vasconcelos Pacheco. Ser e não ser da roça, eis a questão! Identidades e discursos na escola. Salvador: EDUFBA, 2011.

Profissão docente na roça. Salvador: EDUFB,

2015.

SOUSA, Eliseu Clementino de. A arte de contar e trocar experiências: reflexões teórico- metodológicas sobre história de vida em formação. Revista Educação em Questão, Natal, v.25, n. 11, p. 22 - 39, jan./abr., 2006. 